\title{
LAS VENAS DEL TERRITORIO CÁNTABRO. ESTUDIO DE LA RED CAMINERA EN LA GEOGRAFÍA HISTÓRICA DEL PAISAJE
}

\author{
Alberto Ansola Fernández \\ Grupo de Geografía Histórica del Paisaje \\ Departamento de Geografía, Urbanismo y Ordenación del Territorio \\ Universidad de Cantabria
}

\section{RESUMEN}

El trabajo, integrado en una concepción de la geografía histórica del paisaje muy arraigada en la geografía clásica estadounidense, defiende el estudio de los caminos históricos en tanto que vías fundamentales de articulación, en tanto que líneas clave a la hora de conocer la estructura y evolución de los paisajes históricos. Para ello, siguiendo a los autores más relevantes dentro de la caminería histórica española, en primer lugar se pasa revista a las principales y más fructíferas fuentes empleadas en los estudios camineros, tanto documentales (escritas y gráficas), como arqueológicas (vestigios de caminos y de elementos asociados). Después, a modo de síntesis bibliográfica, se analiza el caso de la región de Cantabria a la luz de los trabajos de investigación realizados al respecto, y que han tendido a centrarse en tres épocas históricas (la romana, la medieval-postmedieval y los siglos XVIII y XIX). Por último, se concluye apostando por una ampliación de la escala de análisis, así como de las fuentes de estudio, para intentar llegar a los caminos más locales, los que han tendido a olvidar los estudios camineros regionales $\mathrm{y}$, sin embargo, los que mayor interés tienen para la geografía histórica del paisaje tal cual se plantea aquí.

Palabras clave: Caminos, paisaje, geografía histórica, Cantabria.

\begin{abstract}
This paper, integrated in a conception of historical geography of landscape very stablished in the American classical geography, defends the works on historical roads like fundamental lines of territorial joint, like key lines to understand the structure and evolution of historical landscapes. In this respect, followed the more important authors in the Spanish historical roads, first the paper reviews the main and more productive sources employed in the works of historical roads, as documentary (written
\end{abstract}


and graphic) as archaeological (relics of roads and related elements). After that, like bibliographical synthesis, it analyses the case of Cantabrian region in the light of research works in this respect, which have tended to centre on three historical periods (roman, medieval-postmedieval, and 18 th and 19 th centuries). Lastly, it finishes defending an increase of the scale of research, and in the same way as sources of work, to try to arrive at more local roads, the roads that regional works have tended to forget, and however the more important roads to the historical geography of landscape like this is planed here.

Key words: Roads, landscape, historical geography, Cantabrian region.

\section{La geografía histórica del paisaje y los caminos}

Si se buscan orígenes para una geografía histórica del paisaje, resulta casi inevitable no retrotraerse a los albores de la geografía clásica: de la francesa y, sobre todo, de la alemana. Y no tanto porque sus miembros observasen a los paisajes con una mirada claramente genética; poco conceptualizados y entendidos como síntesis de los elementos visibles de la región por Vidal y sus seguidores, y vistos como conjunto de formas físicas entre los geomorfólogos germanos. Sino más bien porque a ambas escuelas miraron quienes sí les dieron un contenido mucho más evolutivo e histórico. A la vidaliana los grandes ruralistas franceses de los años treinta, caso de Marc Bloch o Roger Dion, que de allí tomaron el término para realizar historia del paisaje propiamente dicha; a la alemana, por su parte, lo hizo el estadounidense Carl Sauer, quien añadió más humanismo y temporalidad al paisaje fisionómico de su tierra parental. Y esta última vía, la estadounidense de Sauer y de la escuela de Berkeley, sin por ello menospreciar en absoluto a los historiadores ruralistas franceses, ni mucho menos a los geógrafos compatriotas que con cierto retraso se acercaron a sus planteamientos, es la que en mayor medida se sigue aquí como línea de acceso a una geografía histórica del paisaje.

Ya desde los años veinte del novecientos, Sauer (1925), en detrimento del área o la región, venía decantándose por el paisaje en tanto que campo principal de estudio de la geografía. Tomando la idea del paisaje fisionómico de la escuela alemana, y sin perder en absoluto de vista la concepción más humanizada de las monografías francesas, planteó la diferenciación entre paisaje natural, el estrictamente físico, y paisaje cultural, el que imprime, modela y modifica constantemente el hombre a lo largo del tiempo. El objetivo de su geografía, a la que no tardaría en bautizar como geografía cultural (Sauer, 1931), estaba en el estudio de las secuencias de paisajes culturales que habían ido formándose sobre la base del natural. Y ya en los años cuarenta, en un discurso inaugural ante la Asociación de Geógrafos Americanos dedicado precisamente a la defensa de la geografía histórica, no sólo insistió en el análisis de los orígenes y procesos de los paisajes culturales como campo productivo de su geografía, sino que concibió a la geografía humana como «Culture-historical Geography» (Sauer, 1941: 360). Una asociación geo-histórica en la que participaron otros colegas suyos estadounidenses: como Derwent Whittlesey (1929) al introducir el término «sequent occupance» en tanto que herramienta para estudiar la ocupación humana del espacio; o como Jan Broek (1943) al proponer la colaboración entre geógrafos e historiadores a la hora de estudiar los cambios paisajísticos derivados de la acción humana; y que acabó por consagrar Andrew Clark (1954: 85-86) cuando en el libro preparado por la Asociación de Geógrafos Americanos a propósito del congreso de la Unión Geográfica Internacional celebrado en Washington, en el cual su participación llevaba el título de 
«Historical Geography», certificó la equiparación de los adjetivos cultural e histórico en el ámbito del grupo de Berkeley ${ }^{1}$.

Pero la aportación de Sauer no se quedó en haber dejado más o menos diseñada una determinada geografía histórica del paisaje. El método morfológico que planteó para llevar a cabo la lectura de las distintas formas culturales de los paisajes conllevaba la combinación tanto de fuentes documentales, y especialmente cartográficas, como un intenso trabajo sobre el terreno, sobre el paisaje heredado. Tal cual sostuvo en una de sus obras (Sauer, 1941: 366-370), el geógrafo (cultural-histórico), además de llevar la documentación del archivo hasta el campo y, una vez allí, intentar ver la dirección y cuantía de los cambios, debía también profundizar en la búsqueda de aquellos elementos físicos que pudiesen aportar información sobre paisajes anteriores. Se refería, más en concreto, a la localización tanto de vestigios culturales, aquellos restos físicos que habían logrado sobrevivir con mayor o menor uso (tipos constructivos, sistemas de campos, viejos caminos, molinos, etcétera), como de formas fósiles, las que ya no eran utilizadas y sólo existían obsoletas o en ruinas (en ocasiones simples huellas de asentamientos humanos o de antiguas actividades agrarias). Con ello consiguió dar a su método morfológico no sólo un cierto carácter regresivo, pues el trabajo de campo partía de los paisajes vigentes para desde ellos adentrarse en los pasados, sino una no menos cierta perspectiva arqueológica, ya que gran parte de ese deshoje temporal se sustentaba sobre el estudio de restos físicos, de fuentes monumentales de información ${ }^{2}$. Luego también llegó al menos a vislumbrar la vertiente arqueológica dentro de la geografía histórica del paisaje, la arqueología del paisaje dentro de la geografía que muy posteriormente han ido concretando autores como Raymond Chevallier (1976) o Paola Sereno $(1981)^{3}$.

Pues bien: dentro de esa vertiente general de la geografía histórica del paisaje, y quizás todavía con más claridad dentro de la más particular arqueología del paisaje, los caminos y las redes camineras, junto al poblamiento, los terrazgos o los montes, suponen un elemento indiscutible de estudio a la hora de recabar información sobre paisajes históricos. De acuerdo con Menéndez y Soria (1994: 68-72), si una determinada comunidad acota jurisdiccionalmente su espacio a través de unos límites, de una red limitánea, y si jerarquiza ese territorio delimitado a través de asentamientos o sedes, del poblamiento, la integración y accesibilidad de todo ello corre a cargo de las vías, de la red viaria. Los caminos no sólo ponen en contacto unas comarcas y regiones con otras (caminos supralocales), sino que articulan internamente una comarca o región al unir núcleos de población entre sí, y a éstos con sus espacios productivos, con sus tierras de labor, sus montes o sus molinos (caminos intralocales). En ese sentido, resulta poco menos que impensable aspirar a desentrañar la estructura, forma y evolución de un paisaje dejando de lado su red caminera y la propia evolución de la misma. En otras palabras: la articulación de los diferentes elementos y espacios del paisaje se encuentra ciertamente en los hilos de la red viaria, auténticas venas del territorio y, en definitiva, del paisaje.

No obstante ese papel fundamental de los caminos en la articulación del territorio, la geografía en general, e histórica en particular, y al menos por lo que se refiere al caso espa-

\footnotetext{
1 Más información sobre Sauer y, en general, sobre la escuela culturalista estadounidense se tiene en Belil y Clos (1983), García Ramón (1985) o Carreras y Vilagrasa (1986).

2 Algo, por otro lado, que también dejaron esbozado historiadores de la escuela francesa de Annales, como Marc Bloch (1931: 32-34) cuando aludió a la necesidad de leer la historia al revés, o como Lucien Febvre (1953: 18) cuando defendió el estudio de los paisajes y sus restos físicos en tanto que detentadores de información histórica sobre la tierra humanizada.

3 Para un mejor conocimiento de la arqueología del paisaje, tanto desde la perspectiva de la geografía como desde otras disciplinas científicas, puede acudirse a Orejas (1995).
} 
ñol, no puede decirse que haya prestado demasiada atención específica a las redes camineras históricas, a pesar de las influyentes y espaciadas llamadas al respecto de Francisco Quirós (1971) o de Ángel Cabo (2002). Es cierto que la mayoría de los estudios regionales han aludido a la importancia de los caminos, pero casi siempre bajo el punto de vista exclusivo de la circulación y de la ordenación espacial de escala regional, sin apenas profundizar más allá de los grandes itinerarios nacionales o, a lo sumo, supralocales ${ }^{4}$. Las aportaciones más específicas o de mayor escala hay que buscarlas más bien en otras disciplinas, como la historia (local muchas veces) o la ingeniería histórica. Dentro de esas disciplinas están incluidas la mayoría de las investigaciones que se han ocupado de forma concreta y por entero de los caminos, y por ello son esas investigaciones inmersas en esas disciplinas las que mayormente vienen mostrando los métodos y las fuentes a seguir en los estudios camineros y, por consiguiente, las que en gran medida ocupan este trabajo. Un trabajo que en su siguiente apartado, y a modo de repertorio metodológico, continúa con un repaso y análisis de aquellas fuentes más utilizadas y más particularmente camineras. Después, con objeto de profundizar en una región y unas investigaciones concretas, y a modo en esta ocasión de estado de la cuestión, se sintetizan los conocimientos que se tienen de la red caminera histórica de Cantabria a través de la bibliografía existente al respecto. Finalmente, al hilo de lo visto con anterioridad, se realizan algunas reflexiones-conclusiones, si no sugerencias, acerca del estudio de los caminos dentro de la óptica de la geografía histórica del paisaje aquí defendida.

\section{Las fuentes para el estudio de los caminos}

Para estudiar los caminos históricos, como en parte ya otease el mismo Sauer (1941: 366-367) en el ámbito de la geografía histórica, y como por lo demás vienen demostrando los trabajos más rigurosos sobre caminería histórica en el contexto español, la vía más fructífera parece encontrarse en el entrecruzamiento de las fuentes documentales y las fuentes arqueológicas. Esa combinación entre el trabajo de archivo y gabinete y el trabajo de campo, en un ir y venir constante de uno a otro, se ha revelado poseedora de una gran facultad, la de proporcionar un continuo reforzamiento de ambos tipos de fuentes entre sí. Los documentos ofrecen abundante información en sí mismos, pero también ayudan a localizar y a interpretar en el campo los restos físicos; esos restos físicos, por su parte, además de contener igualmente algún tipo de información por mínima que sea, posibilitan relecturas más ricas y dimensionadas de los documentos. En nada debe extrañar, por lo tanto, que ese movimiento de vaivén entre unas y otras fuentes no sólo sea deseable, sino que cuanto más intenso tanto más enriquecedor puede resultar para la investigación.

\subsection{Las principales fuentes documentales}

Las fuentes documentales manejadas para trabajos de caminería histórica han sido, desde luego, muy variadas. Aun así, entre ellas han destacado, o en todo caso no han faltado, las más o menos estrictamente camineras. Grupo en el que se incluyen tanto fuentes escritas como gráficas: documentos escritos, archivados o publicados, como los itinerarios de caminos, los relatos de viajes o los informes técnicos relativos a la construcción o mejora viaria; y documentos gráficos, como cartografía antigua, imágenes dispersas o fotografía aérea.

\footnotetext{
$4 \quad$ ¿Herencia francesa? Para Vidal de la Blache (1902), según sugiere en un breve discurso titulado «routes e chemins de l'Ancienne France» (cuya consulta se debe a la atención de Manuel Frochoso), en Francia existían dos tipos de caminos: los grandes o reales, que atravesaban el país y se correspondían con grandes rutas comerciales, políticas o religiosas; y los pequeños, que ponían en contacto unas comarcas con otras.
} 


\subsubsection{Las fuentes escritas}

Dentro de las fuentes escritas, y dejando de lado las más generales que también suelen contener información al respecto (cartularios, apeos, visitas pastorales, protocolos notariales, ordenanzas concejiles, catastros o diccionarios geográficos, por citar las más socorridas), es obligado destacar en tanto que principales documentos específicamente camineros a los itinerarios o repertorios de caminos. Se trata de auténticas guías dirigidas a los viajeros y que, con independencia de unos u otros casos, pueden llegar a recoger desde las distancias entre núcleos de población hasta las características generales de los caminos (si son carreteros o de herradura o si son de orden general o locales) y la localización precisa de puentes, portazgos, ventas y otros elementos asociados existentes a lo largo de los recorridos.

Esa interesante información itineraria, pese a centrarse sobremanera en los grandes ejes y en la pequeña escala (nacional), ha conllevado que su uso haya sido bastante frecuente, sobre todo para época romana, cuando se realizaron los primeros y más arcaicos intentos recopilatorios, y ya con más precisión para las edades Moderna y Contemporánea, cuando alcanzan su apogeo, inmediatamente antes de ser sustituidos en la segunda mitad del siglo XIX por las guías de carreteras. Así, para época romana el más utilizado, por más riguroso aunque no siempre preciso, ha sido el Itinerario de Antonino, un documento del siglo III que llegó a nosotros a través de transcripciones medievales, y que recopila las ciudades de origen y destino de las vías, las estaciones intermedias y las distancias (Roldán, 1975: 19-101). Por su parte, los repertorios de caminos de épocas Moderna y Contemporánea, y sobre todo de los siglos XVIII y XIX, son mucho más numerosos y ricos. Entre ellos quizás cabe destacar el primerizo Repertorio de Villuga del año 1545 y el casi idéntico Repertorio de Meneses del año 1622, pues, a pesar de sus carencias e imprecisiones, en cierta forma, inconclusos otros intentos más ambiciosos y de mayor detalle como la Cosmografía de España de Fernando Colón (1517-1523) (Casado Soto, 1980: 75-85), o incluso las Relaciones Topográficas de Felipe II (1575 y 1578) (Arroyo Ilera, 1998: 203-218), sentaron las bases de los cada vez más completos y documentados itinerarios posteriores (Menéndez Pidal, 1951; Quirós, 1971; Uriol, 1992; y, especialmente, Madrazo, 1984).

Otra fuente escrita con copiosa información sobre caminos la configura la literatura de viajes. Aunque en sentido estricto, y a diferencia de los repertorios, no sean documentos exclusivamente camineros, en casi todos los casos estos relatos describen con mayor o menor detalle un determinado itinerario, y rara es la vez que no se detienen en las características y el estado de las vías, de los puentes, de los pasos de barca o de las ventas. Se trate de las crónicas de viajes regios, que al menos durante la Edad Moderna solían incorporar a escribientes, o de relatos de viajeros ilustrados, románticos o simplemente curiosos, nacionales o extranjeros, muy abundantes en la segunda mitad del siglo XVIII y primera del XIX, prácticamente en todos los casos se alude a los caminos e itinerarios que abarcaron, que no fueron pocos (Madrazo, 1984).

A ambas fuentes, repertorios y viajes, se une una tercera de contenido más variado y disperso, conformada por informes y memorias sobre caminos. Pese a la diversidad de esta fuente, entre sus documentos sobresalen en cuantía los informes técnicos o proyectos de obra, con sus habituales planos, croquis y dibujos anejados, acerca de la apertura de nuevas vías o de la mejora de otras ya existentes. Bien es verdad que no en pocas ocasiones esas obras nunca se acometieron, pero en cualquier caso informan sobre el itinerario, las características y el estado de conservación de los caminos preexistentes y, cuando menos, de las técnicas constructivas planteadas en la apertura de nuevos caminos para un determinado momento histórico (Quirós, 1971 y Madrazo, 1984). 


\subsubsection{Las fuentes gráficas}

Por lo que respecta a las fuentes gráficas, las principales e ineludibles, aunque escasas en número y algo tardías en su desarrollo, son evidentemente las cartográficas. Existen mapas y planos específicos de caminos tanto integrados en informes técnicos, proyectos o memorias, como asociados a algunos repertorios. En este último sentido, desde la segunda mitad del siglo XVIII, cuando los monarcas ilustrados fomentaron el correo como servicio público, muchos de los itinerarios de caminos, que ya de antemano solían estar realizados por empleados de la Posta, adicionaron mapas e, incluso, con el tiempo, el texto escrito fue siendo sustituido por cartas de correos, por cartografías, nacionales o provinciales, donde se representaban las casas de postas, los núcleos de población con estafeta y, por supuesto, las vías para llegar a todos ellos (Bahamonde et.al., 1998).

Con eso y todo, la cartografía más general, la topográfica, donde obviamente nunca faltaban las representaciones viarias, tiene tanta o más información que la anterior. Por citar los ejemplos más convencionales, son muy interesantes para la segunda mitad del siglo XVIII los imprecisos (en los trazados más que en los orígenes y destinos) mapas de Tomás López, y aún más los croquis realizados por sus informantes; lo es asimismo para los años centrales del siglo XIX el Atlas de Francisco Coello; e incluso también lo son para buena parte del siglo XX las primeras ediciones del Mapa Topográfico Nacional, puesto que en sus hojas pueden aún aparecer impresos caminos viejos anteriores a las carreteras (Cabo, 2002: 488-489). Además, estos mapas aportan y georreferencian, con mayor o menor (muchas veces) precisión, abundantes topónimos siempre útiles a la hora de localizar antiguos pasos de caminos ${ }^{5}$.

En otro peldaño más bajo, con menos información y más puntual, se encuentran los croquis e imágenes relacionados de alguna manera con la red viaria. Los informes técnicos y los proyectos, por ejemplo, suelen llevar aparejados dibujos no sólo de la sección y el afirmado del camino propuesto, sino también plantas y alzados de otros elementos asociados como puentes o ventas (Anchón, 1991; Izquierdo, 1996). Asimismo, pueden encontrarse otro tipo de dibujos, más figurativos o esquemáticos, y siempre menos detallistas, en documentos en principio ajenos a los caminos, como son los pleitos sobre límites jurisdiccionales, pues en muchos de ellos, sobre todo los que se prolongaron en el tiempo y acabaron llegando a la Real Chancillería de Valladolid, las vistas de ojos iban acompañadas de dibujos, croquis u óleos en los que los caminos, junto con los núcleos de población y los elementos físicos más notorios (ríos y montañas), se convertían en una referencia locacional y, por tanto, de representación casi obligada (La imagen, 1997). Y, aun siendo todavía más tangencial, tampoco conviene desdeñar la iconografía artística en cualquiera de sus expresiones (dibujos, frescos, relieves o grabados), pues en ella, como ya demostrara José Luis Mingote (1996) en un estudio sobre las evoluciones técnicas y las áreas de uso del carro chillón, pueden aparecer reflejados vehículos y cargamentos que hablan del siempre interesante y no del todo bien conocido ámbito del tráfico.

También la fotografía aérea, tan cercana al trabajo de los geógrafos, puede ser considerada una fuente caminera en el terreno al menos de la prospección. Ya se trate de fotografía oblicua, como la amplia y fructíferamente utilizada por Roger Agache (1971 a modo de ejemplo), o ya sea perpendicular en vuelo bajo, como a la que vienen acudiendo con

$5 \quad$ Siguiendo las síntesis de Ferreira (1988: 25-35) y de Álvarez y Blanco (1999: 498-501), y dejando de lado la hagiotoponimia, las advocaciones de iglesias, monasterios o ermitas con asociación caminera (San Julián el Hospitalario, San Roque, San Cristóbal o Santiago), los topónimos camineros más habituales y seguros vienen siendo calzada, camino, carrera, estrada, carril, calle, concha, horca, puente o venta. 


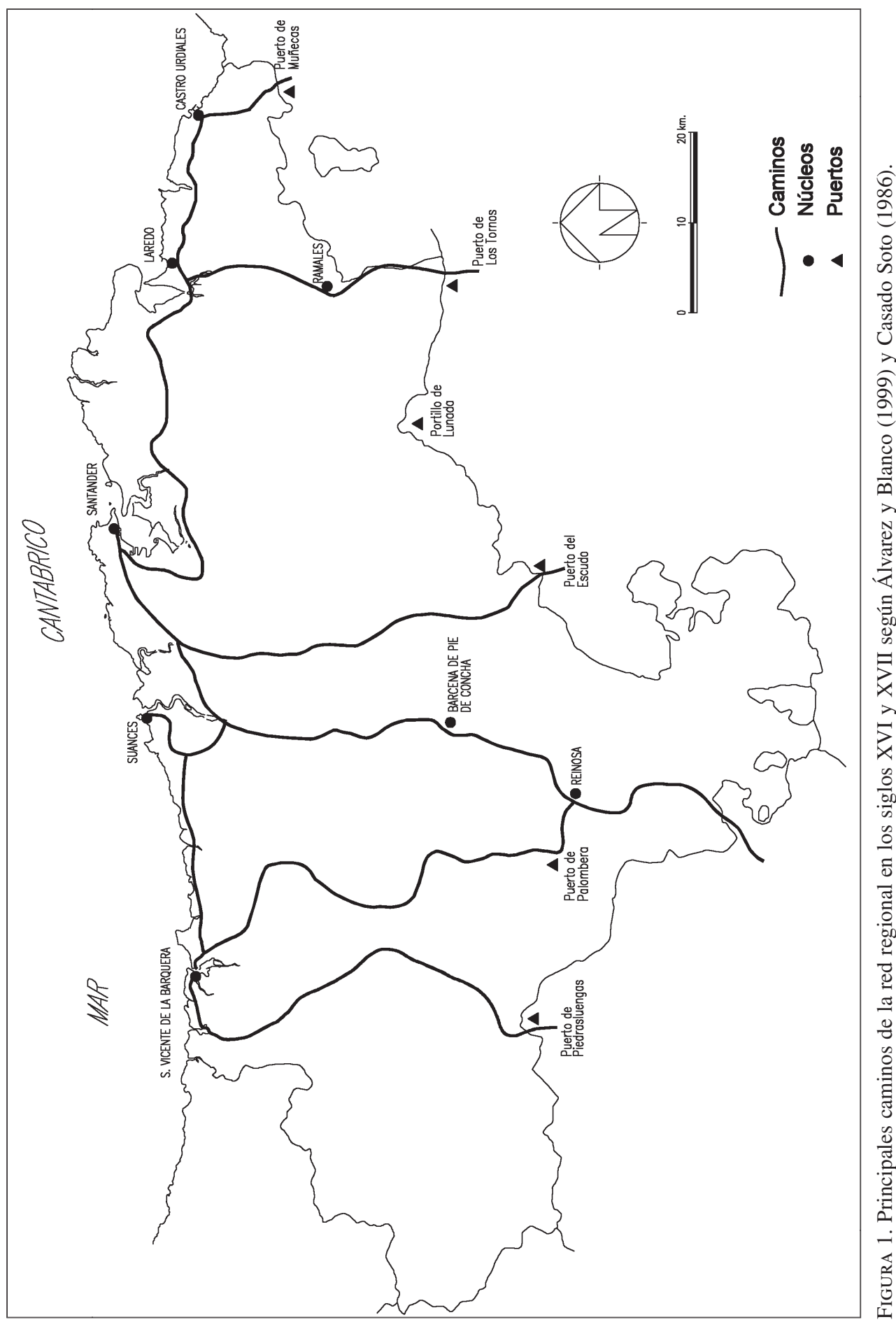


bastante asiduidad y excelentes resultados, entre otros, Josep María Palet (1996 y 1998) y Enrique Ariño et.al. (2004), su servicio es innegable a la hora de prospectar y detectar viejos itinerarios y vestigios de caminos.

\subsection{Fuentes arqueológicas}

Muchos trabajos sobre caminería histórica han añadido a éstas y otras fuentes documentales el análisis arqueológico, el estudio de los restos físicos viarios. Diversos y variados han sido los autores que se han decidido a salir al campo con objeto de buscar y de analizar los vestigios de viejos caminos. Bien es verdad que muchos de esos estudiosos se han centrado en caminos romanos, más escasos en fuentes documentales, o en pequeños tramos dentro de ámbitos locales, emparejando arqueología con valor patrimonial. Pero, quien más quien menos ha aludido a la conveniencia, si no necesidad, de combinar fuentes documentales con trabajo de campo; a la conveniencia de buscar no sólo restos de caminos para verificar itinerarios y comprobar sus características técnicas, sino también restos de elementos asociados al trazado caminero, ya sean relacionados con la defensa del agua, con el jalonamiento o con construcciones de apoyo a los viajeros y de gestión de la propia vía.

\subsubsection{Los restos viarios}

A través de un trabajo de campo intenso, bien apoyado en documentos escritos, cartografías o fotografía aérea, no resulta del todo difícil localizar vestigios de antiguos caminos, pues raro es que carreteras, caminos vecinales o pistas forestales hayan ocupado por entero secuencias anteriores. Una vez hecho esto, esos vestigios permiten constatar fehacientemente itinerarios y, sobremanera, conocer las características constructivas de las vías. Dada la casi nula posibilidad de aplicar sistemas de datación radiométricos, químicos o biológicos a las piedras del camino (salvo que éste se excave y se tenga la inmensa suerte de encontrar bajo el firme algún elemento datable), no es de extrañar que se haya otorgado mucha importancia a los aspectos técnicos con el fin último de establecer cronotipologías ${ }^{6}$, es decir, asociaciones entre determinados modelos constructivos y determinadas épocas históricas. La tarea es compleja si se tiene en cuenta que los caminos, al menos mientras se han mantenido en uso, y debido a los continuos desperfectos ocasionados por el agua y el propio tráfico, han estado constantemente componiéndose, arreglándose y, por tanto, modificándose. Aun así, lo más normal es que esos arreglos no hayan sido totales, por lo que casi siempre pueden aparecer algunas trazas de caminos primigenios.

La mirada a estos vestigios camineros ha solido dirigirse hacia su perfil longitudinal y, en mayor medida, hacia su sección transversal. El perfil interesa porque permite conocer las pendientes que soportaba la vía, y a través de éstas intentar deducir los tipos de vehículos y de cargas que podían asumir sus desniveles, lo cual, siempre y cuando se tenga un buen conocimiento de la evolución histórica de los carros y del tráfico, y no es muy frecuente que así sea, supone una gran ayuda a la hora de relacionar un camino con un período temporal concreto. Pero es sobre todo la sección transversal la que aporta una información más amplia y sustanciosa. Muestra, por ejemplo, el tipo constructivo de la caja: si se dispone alzada en terraplén, hundida en trinchera o explanada en desmonte; si en los taludes o desmontes participan muros de contención; si presenta canalillos o cunetas en los bordes para la conducción del agua; o si aparecen pretiles o mojones

6 El término, como tantas ideas y referencias bibliográficas, está tomado de José Sierra. 
(guardacarros) de balizamiento. Enseña también la anchura, siempre interesante para saber al menos si podían llegar a circular carros y, en ese caso, si podían llegar a cruzarse en tránsito. Y permite ver, igualmente, la estructura y composición tanto vertical (alzado) como longitudinal (planta) del afirmado: si está conformado por varias capas, con su disposición, materiales y grosores, o sólo por una, la de tránsito o firme propiamente dicho; si, en el caso de estar empedrada la capa de rodadura, las piedras tienen una disposición determinada y un tamaño uniforme; o si, de nuevo en caso de enlosado, se distinguen marcas de rodaduras de carros, lo cual, de existir de ambas ruedas, permite conocer la medida del eje del vehículo y, con la debida información etnográfica, llegar hasta el tipo de carro concreto que las causó.

Pues bien, esa mirada arqueológica a los vestigios viarios, con el apoyo de la documentación, al menos ha permitido diferenciar o establecer, y no es poco, tres grandes cronotipologías o tres grandes tipos de caminos históricos: los caminos romanos, los caminos medievales y postmedievales y los caminos reales borbónicos y sus secuelas inmediatas.

De todos ellos, los caminos romanos son probablemente los que más se han estudiado y, sin embargo, los que más interrogantes congregan. Prestigiosos autores, como Menéndez Pidal (1951), Abásolo (1975), Nárdiz (1992) o Magallón (1999), siguiendo trabajos extranjeros y en absoluto exentos de salidas al campo, han mantenido que los caminos de época romana, en un principio, cuando tenían una función más bien militar, se trazaron por interfluvios, asumiendo fuertes pendientes y giros de radio pequeño, pero que con el paso del tiempo y la asunción de la función comercial, buscaron trazados rectos y de escasa pendiente; que su anchura estaba en torno a los cuatro metros; y que su afirmado se componía la mayoría de las veces de varias capas de cimentación, concluyendo en un empedrado uniforme de grandes losas. Por el contrario, otros autores, como Fernández Troyano (1994) y sobre todo Moreno (2004), han puesto en duda esas características. Según Isaac Moreno (2004: 121), la identificación de las vías romanas con calzadas enlosadas parte del siglo XVII, cuando el francés Bergier, en una lectura errónea de Vitrubio, hizo esa asociación, la cual, pese a que ha sido denunciada por diversos autores también franceses, ha calado lo suficientemente hondo como para haber llegado impoluta hasta la actualidad. A juicio de Isaac Moreno, y de acuerdo con su exhaustivo y extenso trabajo de campo y arqueológico, que en cierta medida es avalado por otros estudios (Sillières, 1976 y 1990 o Durán et al., 1999), los romanos, dado que desconocían la herradura, que sus carros eran de cuatro ruedas sin eje giratorio delantero y que transportaban grandes pesos, buscaban perfiles rectos y acomodados a las laderas para no superar el $8 \%$ de desnivel (por encima de esa pendiente era necesario hacer contrafuerza con cuerdas para conducir la carga) y construían caminos anchos, de unos ocho metros con bordillos, terraplenes y cunetas, y muy bien afirmados, con una capa de cimentación de piedras grandes dispuestas verticalmente, otra capa intermedia de piedras medianas y la capa de rodadura de piedra menuda o zahorra natural para facilitar una circulación más cómoda.

Menor, y quizás por ello mayor la unanimidad al respecto, ha sido la atención suscitada por los caminos medievales y, puesto que no parece que durante los siglos XVI y XVII hubiese ninguna innovación, por los caminos abiertos entre los romanos y los reales del siglo XVIII. Se sabe que, aun aprovechándose en parte las vías romanas heredadas, e incluso las prerromanas, se construyeron nuevos caminos más acordes con los nuevos recorridos comerciales y con las nuevas necesidades del tráfico. Esas vías, habida cuenta del predominio de la arriería mulatera sobre la carretería, circunscrita esta última a recorridos cortos y con pequeños carros de escasa carga, no eran tan exigentes como las romanas ni en perfiles suaves, ni en anchuras grandes, ni en firmes cómodos. Así, según Carlos Nárdiz 
(1992: 178), en Galicia los caminos medievales se limitaban a una simple explanación, generalmente sobre fuertes pendientes, a la que seguía la colocación de un firme de piedra pequeña y desordenada sobre el mismo terreno base (encachado). Y algo parecido ocurría en el País Vasco, donde se calzaban los bordes del camino con losas o bloques de piedras grandes y, una vez ganada cierta altura sobre el suelo y formada la caja, se procedía a rellenar la zona central con cascajo, cantos rodados o materiales de desecho como escorias de ferrerías (Barrena, 1991: 172).

A esos caminos de fuertes pendientes, estrechos y encachados les sucedió, ya en la segunda mitad del siglo XVIII, otra tipología bien distinta, la de los caminos reales borbónicos. Las nuevas necesidades de un transporte más rápido y un comercio más cuantioso no podían ser cubiertas con los caminos heredados de los siglos anteriores, razón por la cual los gobernantes ilustrados emprendieron una renovación de la red viaria nacional, de los trazados y de los viales. La idea, siguiendo sobre todo el ejemplo francés, estaba clara: el trazado debía evitar las curvas y pendientes bruscas; la anchura ser doblemente carretera y andar alrededor de los ocho metros; los desmontes llevar amplios muros de contención coronados en grandes losas (cobijas) y en abundantes mojones guardarruedas; el agua esquivarse con numerosos puentes, alcantarillas y canalillos transversales; el firme ganar en flexibilidad para los carros y estar compuesto con piedra machacada recebada con tierra o arena; y el recorrido ir debidamente auxiliado con ventas, fuentes o apartaderos (Madrazo, 1984: 183-233). Dichas características, más próximas a las carreteras actuales que a los caminos medievales, han pasado a caracterizar a los caminos reales dieciochescos. Aunque, hacia finales del siglo, dado el deterioro de algunos de los construidos y la tardanza en el inicio de las obras de otros proyectados, parece ser que se relajaron un tanto los planteamientos iniciales, abriéndose la posibilidad de aprovechar los trazados sinuosos anteriores y de reducir la anchura y la comodidad del firme (Nárdiz, 1992: 219-224).

\subsubsection{Los elementos asociados}

Pero no sólo contienen información arqueológica los restos estrictamente viarios; también poseen interés para el investigador otra serie de elementos de una u otra manera asociados a los caminos. Entre ellos están las infraestructuras relacionadas con la defensa del agua, como son los canalillos transversales, las cunetas, los vados, las alcantarillas y, especialmente, por su mayor complejidad, los puentes. Atendiendo a las características constructivas de los puentes, a aquéllas que continúan identificables tras múltiples desperfectos y arreglos, se ha llegado a asociar distintas tipologías con diferentes épocas históricas. En esa línea, Manuel Durán (2001 y 2004) ha sintetizado la técnica de los puentes romanos a través de algunas constantes: anchura normalmente superior a los cuatro metros, fábrica trabada con hiladas alternas de piezas dispuestas a soga y tizón y con plataforma horizontal o en ligero lomo de asno de sillería almohadillada, dovelas de tamaño uniforme y con agujeros en la sillería, arcos en su mayoría de medio punto, y pilas con tajamares de planta triangular o semicircular en su frente. Características que fueron modificadas a lo largo de la Edad Media, pues el menor tráfico rodado hizo que se buscasen soluciones menos costosas, como la cimentación superficial, los sillares de tamaño más pequeños, arcos apuntados u ojivales, tableros en lomo de burro o curvos, y pasos mucho más estrechos. Por supuesto, con el correr del tiempo estas obras fueron evolucionando y enriqueciéndose hasta llegar a las bóvedas rebajadas y elípticas, las pilas más estilizadas y los tramos de nuevo rectos y anchos de los siglos posteriores (Nárdiz, 1992 y Arenas, 2002).

Otro foco de atención se encuentra en los elementos de jalonamiento o balizamiento del camino; es decir, en los hitos de señalización de distancias, los hitos de delimitación o 
jurisdicción, las señales de nieve, los apartaderos, las fuentes o los mojones guardarruedas. En este caso su interés no reposa tanto en aspectos técnicos y formales, que también, pues por ejemplo las hileras de mojones guardarruedas uniformes son típicas de los caminos reales del siglo XVIII y XIX, sino más bien en la posibilidad de que contengan inscripciones alusivas a un momento histórico o directamente a la fecha de su ubicación. Eso ocurre con los miliarios romanos: además de servir para demostrar la romanidad de un itinerario (en caso de no haber sido movidos de su lugar original), al llevar frecuentemente grabadas alusiones al emperador que en esos momentos había en Roma, permiten, siempre y cuando se puedan interpretar esos epígrafes, una datación bastante fiable (Durán et.al., 1999: 106-139).

$\mathrm{Y}$ algo parecido puede decirse de las edificaciones dedicadas al auxilio de viajeros y animales y a la gestión de la vía, donde caben desde ventas, casas de postas o humilladeros hasta portazgos, fielatos o casetas de peones camineros. Entre todos ellos, quizás los humilladeros y las ventas, por su mayor regularidad y perdurabilidad, sean los más interesantes. Los humilladeros, por transformados que puedan estar, normalmente se han mantenido en su sitio y, aparte de indicar el paso de un camino a su pie, no es del todo infrecuente que tengan inscripciones relativas a las personas o hermandades que los mandaron construir y a la fecha en la que esto se hizo ${ }^{7}$. En cuanto a las ventas, además de marcar también el paso de un camino, si se encuentran en ruinas o sin transformar, un mero sondeo arqueológico puede posibilitar la consecución de materiales datables, y con ello información sobre su período funcional, así como la reconstrucción del edificio, lo que, a tenor de los muchos tipos de construcciones y de servicios que cupieron bajo esa denominación (Madrazo, 1984: 455-501), a buen seguro que ayuda a la hora de conocer mejor la función y el tráfico del camino.

\section{Una aproximación a la red caminera histórica de cantabria}

Vistas a muy grandes rasgos las principales fuentes que los estudios de caminería histórica vienen utilizando, parece que no esté de más profundizar en un ámbito espacial concreto, pararse a analizar los resultados que esos trabajos han arrojado en una determinada región como es la actual comunidad autónoma de Cantabria. El conocimiento más cercano que el autor tiene de dicha región, y una producción bibliográfica caminera que puede considerarse relativamente extensa, avalan esa elección. Bien es verdad que ese bagaje editorial es muy variado y poco uniforme, combinándose unos trabajos sobre el conjunto de la red caminera con otros más locales sobre un camino, un tramo del mismo o un elemento asociado, pero su consideración conjunta permite ya acumular bastante información sobre la evolución de la red viaria regional. Los párrafos que siguen pretenden ser, por consiguiente, un repaso a las principales aportaciones bibliográficas al respecto y a las distintas fuentes y miradas por ellas empleadas, una especie de síntesis crítica o, si se prefiere, un estado de la cues-

$7 \quad$ Para el ámbito castellano Sánchez y González (2003: 6-18) han establecido una evolución tipológica desde las cruces bajomedievales a las capillas de planta central de los siglos XVI y XVII y a las de planta axial del XVIII. Por otro lado, para el caso de Cantabria se han establecido tres tipologías de humilladeros: los «santucos de las Ánimas», con cruz de piedra con abundante iconografía y bajo capilla, los «santucos de la Pasión», con cruz de madera con menos iconografía y capilla más modesta, y «las cruces», sin apenas iconografía e integradas en pequeñas capillas (Sánchez Trujillano, 1976, 1977-1978 y 1979-1981). A partir de esa diferenciación, dados los distintos rangos constructivos e iconográficos que parece haber entre unos humilladeros y otros, puede pensarse en una posible asociación entre esos tipos y la importancia del camino en el que aparecen, si bien hasta la fecha no se ha conseguido comprobar ninguna correlación en ese sentido. 
tión articulado a través de los tres grandes períodos históricos de la caminería hispánica: el romano, el medieval-postmedieval y el ilustrado-contemporáneo.

\subsection{La controversia acerca de los caminos romanos}

Por más que los pueblos prerromanos debieron tener su propia red de caminos o, cuando menos, sus sendas de comunicación, la historia de la caminería cántabra, como por lo demás la de otras regiones, comienza por la red romana ${ }^{8}$. Uno de los primeros y más influyentes trabajos al respecto es el de Fermín Sojo y Lomba (1947). Este ingeniero militar, amparándose sobre todo en una concepción muy amplia de la toponimia caminera regional (donde cabían carrera, castillo, concha, cuarta, estrada, guinea, horca, muño, muno, muñeca, quintana, sedo o viesca), y asociando esa toponimia de origen latino con la época romana, llegó a establecer hasta nueve vías de ese momento histórico en territorio cántabro (vía de Agrippa o de la Costa, calzada del valle de Mena a Castro Urdiales, calzada de Los Tornos, vía del Portillo de La Sía, vía del portillo de Lunada, camino del Escudo, camino por el Besaya, entrada por Piedras Luengas y vía paralela a la de Agrippa), además de apuntar otras vías secundarias y diversos ramales de unión entre todas ellas. A partir de ahí, esas vías, y en general cualquier camino empedrado (y hay que tener en cuenta que en Cantabria por la abundancia de lluvias y las acusadas pendientes lo estaban casi todos), pasaron a considerarse de origen romano aun sin existir apenas evidencias al respecto. Así, el arquitecto Javier González de Riancho (1988), merced a un pormenorizado trabajo de campo, reconstruyó el itinerario de un camino viejo entre Santander y el puerto de El Escudo a lo largo del interfluvio de los ríos Pas y Besaya, y lo calificó de romano por el mero hecho de estar enlosado y por haber aparecido algunas monedas y medallas romanas en sus cercanías. También, desde hace al menos cinco años, vienen realizándose campañas arqueológicas en la denominada cambera de los Moros, un camino empedrado que cruza la sierra del Escudo de Cabuérniga, y que igualmente ha sido considerado romano por estar empedrado con grandes losas, hasta el punto de contar con un centro de interpretación en San Vicente del Monte, donde se muestran las características de la vía y las técnicas y herramientas supuestamente empleadas en su construcción ${ }^{9}$. Además, a éstos habría que unir aquellos otros caminos que no han sido objeto de estudio específico, pero que se suponen romanos, e incluso se promocionan y señalizan como tales, llegando en algunos casos al absurdo, como ocurre en el puerto de Los Tornos, en la recientemente renombrada «ruta de Carlos V», donde un panel informativo del Gobierno de Cantabria anuncia como romanos un tramo de camino y un puente pertenecientes al camino real de Los Tornos y realizados en el siglo XIX ${ }^{10}$.

Entre esas obras dedicadas a los caminos romanos, sin duda la más rigurosa es la de los historiadores Iglesias y Muñiz (1992). Estos autores, ante la ausencia de vías que surcasen la región en el Itinerario de Antonino, recurrieron a otras fuentes más secundarias y a un detallado trabajo de campo que, unido a los restos arqueológicos que ya se conocían, les ha llevado a desechar algunos caminos (el de El Escudo, por ejemplo) y a establecer, no sin cautelas, seis vías con una presunta utilización romana. De todas ellas,

8 La única referencia conocida respecto de los caminos prerromanos no pasa de la afirmación hipotética de que debía haber «una red viaria consolidada en momentos inmediatamente anteriores a la presencia romana» (Muñiz, 1999: 295-296).

9 Ya en la campaña arqueológica del verano de 2004 sus directores, Alberto Celis y Lino Mantecón, cuestionaban la romanidad del enlosado actual. El diario montañés, 11-IX-2004.

10 Algo denunciado por Isaac Moreno (2004: 231) conforme al trabajo de Manuel García Alonso (2002a). 
la más importante era la que desde Herrera de Pisuerga se dirigía a la ciudad de Iuliobriga (en las cercanías de Reinosa), para desde allí descender por el valle del Besaya hacia los puertos de Suances y de Santander (Portus Blendium y Portus Victoriae respectivamente). $\mathrm{Su}$ existencia la fundamentan en la constatación de la misma en el controvertido Itinerario del Barro (unas tablillas de barro con epigrafía encontradas en Astorga y que los expertos no se ponen de acuerdo sobre su autenticidad), la aparición de algunos restos materiales de origen romano en su recorrido (incluido un fragmento de un miliario), y la conservación de algunos paños de camino bien enlosado, como el de Pie de Concha-Mediaconcha-Somaconcha (entre Bárcena de Pie de Concha y Pesquera), que tras un sondeo arqueológico mostró una anchura entre tres y cuatro con diez metros, un empedrado de grandes losas muy homogéneas y bien encajadas, y diversas huellas de carros en algunos puntos de sus casi cinco kilómetros y medio de recorrido. De esa vía principal salían dos variantes menos documentadas: la variante del Burejo, que desde Herrera de Pisuerga se prolongaba hasta Cervera y luego hasta Liébana y la costa, amparada en la aparición de restos cerámicos en la zona palentina y una estela funeraria en Liébana; y la variante del collado de Somahoz, que desde Mercadillo se dirigía al collado de Somahoz para descender por el valle del Saja hacia la costa, y de la que se conservan abundantes lienzos de empedrado tanto en el lado palentino (también estudiado por Fonseca, 1985) como en el cántabro entre la Venta de Tajahierro y Bárcena Mayor (Prats y Sánchez, 1985) o en la cambera de los Moros ya citada. Otra vía unía Herrera de Pisuerga y Iuliobriga con el puerto de Castro Urdiales (Flaviobriga) por Valmaseda, el puerto de Las Muñecas y Otañes, donde se han encontrado varios miliarios, aunque no restos viarios. También mencionan la ruta del Ebro, una hipotética vía sin apoyatura documental y muy escasa arqueológica (algunos segmentos ligeramente empedrados y un miliario hallado en las cercanías) que enlazaba Iuliobriga con el valle del Ebro. Por último, se menciona la vía de Agrippa, un camino paralelo a la costa que aparece mencionado en el Itinerario de Rávena y que los autores, habida cuenta de los problemas de autenticidad que concita la fuente y de la profundidad que alcanzan los estuarios cántabros, no ven muy posible, decantándose más bien por la hipótesis de un transporte marítimo de cabotaje entre los puertos o, a lo sumo, por la combinación del tráfico marítimo con pequeños tramos terrestres.

La mayoría de estas vías, sin embargo, han sido puestas en duda recientemente por Isaac Moreno (2004: 227-231). En su opinión, además de tener un escaso y frágil apoyo documental, los restos viarios conocidos no obedecen en absoluto a la lógica técnica e ingenieril de los caminos romanos: ni las pendientes, muy por encima en algunas ocasiones del $8 \%$; ni la anchura, generalmente por debajo de los cuatro metros y hasta de los dos metros; ni el afirmado, carente de capas de cimentación y coronado con un enlosado impracticable para los carros de la época. Así, a la cambera de los Moros, en la variante del collado de Somahoz, dadas sus fuertes pendientes y su firme por completo empedrado, la considera un camino de mulas y ganado imposible para los carros. Y tampoco al tramo entre Bárcena de Pie de Concha y Pesquera, el más espectacular y representativo de la región, lo ve apto para el tráfico de carros romanos por similares razones, relacionando las huellas de rodadura en su empedrado con el tránsito de carros locales de montaña ${ }^{11}$.

11 Además, en un sondeo arqueológico realizado el año 2003 entre Pesquera y Somaconcha con motivo de las obras de la autovía A-67 se hallaron restos cerámicos debajo del empedrado y su datación mediante termoluminiscencia los ubicó en el siglo XVIII (Moreno, 2004: 228 y 230). Esto resulta cuando menos sorprendente, pues mediado ese siglo ya estaba abierto el camino real de Reinosa, al otro lado del río Besaya, lo cual lleva a pensar más bien en restos asentados en un arreglo del camino. No hay que olvidar que el topónimo «concha» alude a camino empedrado, y que la fundación de los núcleos Pie de Concha, Mediaconcha y Somaconcha es anterior al siglo XVIII. 
Sí otorga romanidad, por el contrario, y pese a carecer por el momento de restos viarios, al itinerario por el puerto de Las Muñecas hacia Castro Urdiales, pues la aparición de un número significativo de miliarios lo permite.

Desde luego, entre estas posiciones tan contrapuestas, mientras no se realicen nuevos hallazgos y aumente el conocimiento histórico de la época, caben muchas conjeturas. Puede pensarse que no existía comunicación directa entre La Meseta y la costa cántabra, razón por la cual no se registra ninguna vía en el Itinerario de Antonino. Más lógico, a tenor de las relaciones comerciales entre La Meseta y los puertos cántabros que parecen poner de manifiesto restos cerámicos y numismáticos hallados en Iuliobriga, y a tenor de los miliarios descubiertos en diversos puntos, es pensar que sí había alguna vía directa de comunicación, pero que ésta ha podido perderse, o simplemente que tenía un rango más secundario que las del interior de la Península, y por eso no aparece reflejada en el Itinerario de Antonino. Incluso, si esto fuese así, cabe también la posibilidad de que a estas vías más secundarias se les aplicase otras técnicas constructivas más modestas y mejor adaptadas al terreno húmedo y abrupto del Norte, aunque ello supusiese modificar los sistemas de transporte y su capacidad. Y todo esto sin olvidar la posible utilización y acondicionamiento de caminos prerromanos para tránsitos a pie o de poca carga. De hecho, un conocimiento más profundo del tipo de tráfico que había entre la costa cantábrica y La Meseta a buen seguro que despejaría muchos de estos interrogantes.

\subsection{Entre los caminos romanos y los reales borbónicos}

A lo largo de la Edad Media, a medida que fueron surgiendo nuevos asentamientos y mayores vínculos de intercambios comarcales, a medida que fueron desarrollándose una mayor ocupación del espacio y una nueva ordenación del territorio, es más que probable, casi seguro, que debió configurarse una novedosa red viaria regional, una red tanto más rudimentaria en la factura de sus caminos como más densa en las ramificaciones de sus trazados. Es muy posible que, al menos en la Alta Edad Media, se utilizasen total o parcialmente vías romanas, como se ha demostrado arqueológicamente en Galicia, en la vía Nova de Orense, donde por una parte del fondo de una caja romana transcurre un camino estrecho y encachado para carros del país y muy fácilmente de origen medieval (Durán et.al., 1999: 53-55). Pero también se construyeron nuevos caminos y trazados para comunicar aldeas de reciente creación, o simplemente para acceder a espacios de novedosa puesta en producción, tal como lo pone en evidencia Gómez Bárcena (2002: 120-123) en su estudio sobre una presura en Toporias (Udías), pues dos documentos del siglo X del Cartulario de la Antigua Abadía de Santillana del Mar marcan como uno de los límites de esa presura el camino viejo (itinere antiqua), que el autor cree romano por haberse encontrado monedas y herramientas de trabajo de esa época en unas minas cercanas, y que en cualquier caso demuestra la apertura de un camino nuevo. Incluso, algunas de las vías supralocales pudieron recuperar (si es que no se había hecho ya en el período romano) viejas sendas prerromanas a juzgar por la bastante habitual coincidencia espacial entre itinerarios de caminos viejos y secuencias de túmulos megalíticos o mámoas, verificada en Galicia (Bello et.al., 1987: 107-121 y Nárdiz, 1992: 168-172), en el País Vasco (Barrena, 1991: 66), y también en Cantabria, en el valle de Lamasón (Ansola et.al., 2002: 100-101) o en el presunto camino romano de El Escudo ${ }^{12}$.

12 En diversas partes de su recorrido, González de Riancho (1988) se encontró con restos de estelas, de túmulos megalíticos y de asentamientos castreños. Esto, unido a su trazado en altura, su estrechez y su firme encachado acercaría el camino a época prerromana y medieval más que a la romana, con sólo unas monedas sueltas a su favor. 
Desgraciadamente, a pesar del indudable interés de la caminería medieval, las investigaciones al respecto son más bien escasas. El trabajo que más allá ha ido en el intento de vislumbrar la red viaria medieval obedece al esfuerzo de Álvarez y Blanco (1999). Sin embargo, dicho estudio está lastrado por su escasa extensión y su no menos escasa profundidad, pues, como las dos medievalistas aclaran, su pretensión es la de poner sobre la mesa una metodología de análisis que pueda servir como punto de partida para futuras investigaciones. Por ello dedican buena parte de su trabajo a reseñar, comentar y ejemplificar las principales fuentes (escritas, arqueológicas, cartográficas e iconográficas) para el estudio de la caminería medieval. Aun así, con la documentación escrita de la que disponían, con la localización de torres o fortificaciones medievales, y con la toponimia caminera conservada en la actualidad, se aventuraron, con todas las reservas y sin trabajo de campo, a esquematizar cartográficamente la red viaria medieval de la región. El resultado puede resumirse en cinco vías principales, todas ellas de la costa hacia el interior (San Vicente de la BarqueraCervera de Pisuerga por el valle del Nansa y el puerto de Piedras Luengas, Santander y Suances-Aguilar de Campoo por el valle del Besaya y Reinosa, Suances-Reinosa por el valle del Saja y el puerto de Palombera, Laredo-Burgos por el valle del Asón y el puerto de Los Tornos ${ }^{13}$, y Castro Urdiales-Valmaseda por el puerto de Las Muñecas), además de toda una serie de vías secundarias destinadas a poner en contacto las anteriores entre sí.

Una red viaria que, a grandes rasgos y en cuanto a sus ejes principales, no debió sufrir apenas variaciones durante los siglos XVI, XVII y primera mitad del XVIII. Así, los grandes ejes de comunicación siguieron siendo los que unían los puertos de las villas marineras con el interior de la Península. En ese sentido, para los siglos XVI y XVII Casado Soto (1986: 50-56) destaca el camino de Laredo a Burgos por el puerto de Los Tornos, el de Santander a Reinosa por el valle del Besaya, el de Santander a Burgos por El Escudo, el de San Vicente de la Barquera a Reinosa por el valle del Saja y el transversal y paralelo a la costa que unía a las villas pesqueras. Una red principal que, unida con la medieval de Álvarez y Blanco (1999), se sintetiza en la Figura 1.

Hay que tener en cuenta que en esos siglos postmedievales los gobernantes prácticamente no prestaron atención a los caminos más allá de algunas providencias puntuales, por lo que el peso del mantenimiento y composición de las vías recaía por entero en los concejos, y éstos es de suponer que no pasasen de arreglos más superficiales o más profundos de los caminos heredados ${ }^{14}$. Según Pablo Alzola y Minondo (1899: 190), sólo coincidiendo con viajes regios o de personajes ilustres y con exigencias militares de transporte de artillería los gobernantes ordenaron el arreglo de determinados tramos o de puentes. Eso sí, algunas de esas intervenciones debieron recaer sobre caminos cántabros por lo que toca a viajeros ilustres, pues tanto Carlos I, en tres ocasiones (la primera por el valle del Saja, la segunda por el del Besaya y la tercera por Los Tornos), como la princesa Ana de Austria en 1570 o el príncipe de Gales en 1623 recorrieron la región desde el mar Cantábrico hasta Castilla. Y también por lo que concierne a tráfico de artillería, ya que en el año 1522 el propio Carlos I, ante el levantamiento de las Comunidades de Castilla, hizo llegar al puerto de Santander desde Flandes un gran tren de artillería formado por 28 falconetes, 18 cañones,

13 Sobre este camino se planteó, a finales del siglo XV y de la mano de los mulateros de Castilla, un pormenorizado proyecto de mejora (con nuevas variantes de menos desnivel, ensanchamientos de calzada, muros de mampostería de encajonamiento, mojoyas de piedra y árbolado para señalización en tiempo de nieves o nuevos puentes de piedra y madera), pero que, pese a tener el visto bueno del Consejo Real, avanzado el siglo XVI aún no se había llevado a cabo por diversos y dilatados problemas en los repartimientos (Molénat, 1971: 142-162).

14 Uno de esos arreglos más profundos lo protagonizaron ya en 1740 los valles de Rionansa y Lamasón, que acondicionaron como carretero el camino que unía el puerto de San Vicente de la Barquera con Castilla por el valle del Nansa y el puerto de Piedras Luengas (Maiso, 1990: 108). 
16 serpentinas, una bombarda, un trabuco y varios tiros, en cuyo traslado desde Santander a Valladolid, siempre según Alzola y Minondo (1899: 168), se emplearon un total de 2.128 mulas y 1.074 hombres para guiarlas, además de varias decenas de azadoneros para habilitar los malos pasos del camino ${ }^{15}$.

Fuera ya de conjeturas, lo demás que se conoce con anterioridad a la segunda mitad del siglo XVIII viene de la mano de estudios más localizados. En su investigación sobre los caminos romanos burgaleses, Abásolo (1975: 237 y 246) observó restos de dos caminos antiguos, sin suficiente base para considerarlos romanos pese a estar empedrados, que se adentraban en Cantabria por los puertos de Lunada ${ }^{16}$ y de Los Tornos. Este último, bajo la denominación de sendero Enhiesto ha sido más recientemente estudiado y catalogado de medieval por García Alonso (2002a: 199-201), quien ha destacado como principales características su estrechez, sus fuertes pendientes y revueltas, y su firme de piedra encachada. La reconstrucción del puente de Santa María de Cayón entre los siglos XVI y XVII seguida por Manuel Vaquerizo (1988) constata que por ese puente pasaba un camino real que unía la costa con el interior, pues por él pasaban mercancías (trigo y vino principalmente) procedentes de Andalucía, Extremadura, La Mancha, Castilla la Vieja y La Rioja. Otro camino real, esta vez paralelo a la costa, a la altura de Comillas y Ruiloba, es referenciado por Patricio Guerín (1971) al estudiar un pleito en relación con la apertura de una nueva venta en la primera mitad del siglo XVII. Posiblemente el camino costero que ya pasaba por Puente Agüero en la primera mitad del siglo XVI (Ruiz y Del Jesús, 2001: 13). Y a éstos, y evidentemente a otros sin investigación, habría que añadir vías más secundarias y locales, entre las que se encuentran, por ejemplo, los caminos carboneros localizados por García Alonso (1999: 101-102) en montes de los valles de Miera, Soba y Ruesga, caracterizados por un enlosado en los bordes de la caja y una anchura suficiente para el tráfico de carros, y que al estar en función del abastecimiento a las fábricas de cañones de La Cavada y de Liérganes, muy probablemente fuesen anteriores, o cuando menos coetáneos, a la segunda mitad del siglo XVIII ${ }^{17}$.

\subsection{Los caminos anteriores a las carreteras}

A partir de los años centrales del siglo XVIII, cuando los monarcas de la Ilustración se plantearon la intervención directa en materia caminera y la renovación de la red viaria nacional, una nueva concepción itineraria y formal estaba abriéndose paso. La primera obra que inició esa política carreteril, y que junto con su coetánea del Guadarrama sirvió de ejemplo técnico a seguir para proyectos sucesivos, la constituyó el camino real de Reinosa, el que enlazaba Santander con esa localidad campurriana a lo largo del valle del Besaya. Dicha vía, concebida en origen para unir Burgos con el puerto de Santander, por donde las

15 Aunque sin más información al respecto, una carga tan pesada tuvo que dejar arreglos considerables en el camino elegido, que al parecer fue el de Santander a Reinosa por el valle del Besaya, o al menos ese fue el camino de vuelta del monarca y, presumiblemente, con él, el de la artillería. De ser así, cabe preguntarse si el estupendo lienzo de enlosado que se conserva entre Bárcena de Pie de Concha y Pesquera, y hasta sus huellas de rodadura de carros, no tienen algo que ver con la composición y el uso del camino para la ocasión.

16 Aun tratándose de restos viarios que efectivamente parecen bastante antiguos, no está claro que antes del siglo XVIII existiese camino por el portillo de Lunada, pues según atestiguan documentos consultados por Izquierdo (1986: 163), en el año 1692 los vecinos de Santander y de Trasmiera hicieron un intento, baldío, de abrir camino por Lunada en dirección a Espinosa de los Monteros.

17 Otro camino carbonero, esta vez en el enclave oriental de Villaverde de Trucíos y asociado al abastecimiento de ferrerías locales, ha sido descrito con trazado sinuoso, anchura entre unos dos y tres metros, y firme de empedrado escaso e irregular (Ruiz y Fernández, 2002: 152). 
lanas castellanas debían salir hacia Europa, y de cuya gran influencia económica ya se ha ocupado en extenso la historiografía regional, empezó a construirse en el año 1749 y fue abierta al tráfico en 1753. Sus características formales poco o nada tenían que ver con los caminos regionales preexistentes. Tal como lo documenta Palacio Atard (1960: 79-81), uno de sus primeros investigadores, el camino, de anchura nunca inferior a los ocho metros y provisto de 18 puentes, 974 alcantarillas y 6.449 mojones guardarruedas, estaba formado por muros de contención bien ajustados para delimitar la caja, que luego era rellenada con una capa de cimentación de piedra crecida ordenada y, sobre ésta, una capa de rodadura de piedra pequeña machacada hasta conseguir un cascajo menudo que, tras ser recebado con arena, formaba un piso dulce para los carros y levemente alomado en sección para derivar el agua hacia las cunetas laterales. Posteriormente, ya bajo la gestión del Real Consulado de Santander, y ya como camino esencialmente harinero, sufrió algunos arreglos y modificaciones (entre otros, Menéndez, 1987: 26-29), pero mantuvo esas características, aún bien observables en el tramo conservado entre Bárcena de Pie de Concha y Pesquera, en la margen fluvial opuesta al camino presuntamente romano ${ }^{18}$.

La vía que siguió en importancia a la de Reinosa fue la de Santander a La Rioja, conocida desde la capital regional como camino de La Rioja. La iniciativa, abierta por Floridablanca, aprobada por Carlos III en el año 1788 y respaldada por el Real Consulado de Santander, suponía abrir el puerto santanderino y la propia región al tráfico de mercancías provenientes de la provincia burgalesa y, sobremanera, de La Rioja y, en general, del valle del Ebro. En el primer proyecto, realizado por los arquitectos de Marina Juan y Francisco Solinís, y del que ha dado buena cuenta Rafael Izquierdo (1996: 107-146), el camino era trazado por el valle del Miera y el portillo de Lunada, en dirección a Espinosa de los Monteros. Sin embargo, después de muchas disputas y no pocos intereses personales cruzados, en el año 1800 fue abandonado ese trazado inicial y derivado su itinerario por el valle del Pas y el puerto de El Escudo, por donde definitivamente se construyó ya adentrado el siglo XIX. De ese camino por el Pas, el real de La Rioja, poca información se tiene; son más conocidos los detalles del proyecto inicial y de los problemas en su ejecución que las características del camino construido, muy probablemente oculto bajo la actual carretera nacional y sin restos físicos localizados hasta la fecha.

El tercer gran proyecto de camino real lo constituyó el de Laredo a Burgos por el valle del Asón y el puerto de Los Tornos. Este trazado, tras perder la batalla con el de Santander-Reinosa por convertirse en la arteria principal de unión entre Castilla y el Cantábrico, fue objeto de numerosos planos, proyectos y estudios financieros a lo largo de la segunda mitad del siglo XVIII, pero las obras no se aprobaron hasta 1798, y no se concluyeron hasta 1826 (Madrazo, 1984: 253). Los restos del mismo a la altura del puerto de Los Tornos, compuestos por algunos tramos y varias ventas y fuentes, identificados y estudiados por García Alonso (2002a: 201-203), denotan unas características similares a las del camino de Reinosa, con pendientes más suaves que el vecino camino medieval, anchura suficiente para el cruce de carros, muros de contención, firme de piedra menuda recebada con tierra entre hiladas de losas, y cunetas y alcantarillas para defensa del agua. Y también en las cercanías de Ramales de la Victoria se conserva otro tramo con abundante obra de contención, pues está prácticamente adosado a un muro rocoso muy vertical, y con buena anchura, firme de piedra pequeña recebada con tierra y mojones guardacarros en su talud descendente. Ahora bien, este mismo tramo, dando una curva para descender hacia el núcleo de Ramales de la

18 García Alonso (1994 y 2002b: 51-52) mantiene la hipótesis de que la apertura del camino real supuso un cierto reparto poblacional hacia su trazado, como parece sugerir el abandono de algunos núcleos emplazados en las cercanías del camino viejo hasta entonces en uso. 
Victoria, y cuando menores son los obstáculos del relieve, reduce esas características a una anchura muy inferior y a un firme más elemental de piedra mediana y encachada, lo que puede dar pie a pensar que no en todo su recorrido reprodujo la misma factura; es decir, que las obras pudieron dividirse entre la apertura de nuevos tramos y el acondicionamiento o aprovechamiento sin más de otros ya existentes.

Por lo demás, ahí parecen acabar los caminos reales borbónicos regionales. Es cierto que una excavación de urgencia en Hualle (Valdáliga) dejó al descubierto una traza de vía con similitudes formales a las de Reinosa y Los Tornos, y que los arqueólogos creen que es parte de un camino real costero entre San Vicente de la Barquera y Santander (Crespo et.al., 1999). Pero a falta de otras evidencias físicas, las documentales conocidas hasta el momento llevan más bien a una serie de proyectos de iniciativa local relacionados con el arreglo (en Valderredible, Toranzo o Rionansa) o construcción (en Ruesga para sustituir pontones de madera y en San Vicente de la Barquera, Pesués y Unquera para sustituir barcajes) de puentes y con la apertura de variantes a caminos preexistentes (en Polaciones o Cabuérniga) (Trueba, 1993: 185-353). En este último caso, en 1757 el valle de Polaciones planteó un camino en terreno palentino, entre el puerto de Piedras Luengas y Cervera de Pisuerga por La Pernía, y de ahí hacia la provincia de León, con objeto de poder suministrar a los alfolíes leoneses, el cual al parecer se acabó concretando, si bien a los valles vecinos, cántabros y palentinos, les resultaba más cómodo y sólido el viejo. En cuanto a la variante entre Cabuérniga y Reinosa, en 1797 los vecinos del valle de Cabuérniga pidieron permiso para abrir un camino a su costa por la braña de Lodar hacia Aradillos que evitase el complicado puerto de Palombera, y así poder exportar con comodidad sus aperos de madera y recibir el trigo y el vino castellanos, y cuya ejecución no está en absoluto clara por más que Santos Madrazo (1984: 254) la haya ubicado avanzada la centuria siguiente.

En definitiva, los caminos reales de la segunda mitad del siglo XVIII y, en su prolongación, de la primera mitad del XIX no parece que modificasen gran cosa la red viaria regional, aparte de una mayor y más clara jerarquización de los pasos hacia La Meseta. De hecho, a tenor de los estudios comentados, a medida que expiraba el siglo XVIII y se adentraba el XIX las actuaciones interregionales tendieron a centrarse en arreglos o variaciones parciales de caminos ya existentes, por lo que, de ser así, tampoco puede considerarse que la tan loada técnica de los caminos reales borbónicos se reprodujese más allá de las vías de Reinosa, El Escudo y Los Tornos, o de algunos remiendos o rondas a caminos antiguos. Para ello seguramente hubo que esperar a que avanzase más el siglo XIX, si no a sus postrimerías y los inicios del $\mathrm{XX}$, cuando sin solución de continuidad esa técnica evolucionaba hacia las carreteras modernas.

\section{Los caminos y la geografía histórica del paisaje}

A pesar de sus mayores o menores aportaciones y de sus incapacidades para dar respuesta a no pocos interrogantes, todos estos trabajos brevemente sintetizados han configurado en su conjunto un conocimiento bastante amplio de la caminería histórica cántabra. Esto es tan cierto como loable. Sin embargo, volviendo sobre los párrafos iniciales, dichas aportaciones, aunque de gran ayuda, no han terminado de desembocar en un estudio de los caminos más fructífero para una geografía histórica del paisaje como la aquí concebida. La gran mayoría de estos trabajos han centrado sus investigaciones sobre caminos supralocales o suprarregionales, sobre ejes principales de acceso y salida de la región, con resultados muy interesantes para la historia y la geografía en general, pero no tanto, en efecto, para la geografía histórica del paisaje en particular. El estudio de los caminos como elementos fundamentales de los paisajes históricos reclama otra escala de análisis más local capaz 
de abarcar vías más secundarias, pues, sin menospreciar en absoluto la importancia de los grandes ejes de comunicación, son los caminos entre núcleos de población y entre éstos y sus espacios productivos los que terminan por conformar la red interna dentro de una comarca, los que definen la articulación interna de un territorio determinado. En esa línea, la geografía histórica del paisaje demanda un cambio de escala, una ampliación escalar que posibilite la siempre difícil tarea de acercarse a esos otros caminos más locales o comarcales. Y para ello es necesario ampliar también las fuentes de trabajo y la mirada hacia las mismas.

Dicha ampliación afecta, desde luego, a las fuentes documentales. Sin dejar de tener en cuenta las reseñadas aquí, y como vienen demostrando algunos trabajos de índole más regional o local, el cambio de escala supone recurrir con más asiduidad y perseverancia a fuentes no específicamente camineras, a fuentes más generales, dispersas y costosas, pero muy ricas la mayoría de las veces en referencias camineras concretas. Supone recurrir, por ejemplo, y sin ánimo de pormenorización, a cartularios, a apeos, a ordenanzas concejiles, a protocolos notariales, a diccionarios geográficos, a guías informativas, a topografías médicas, a catastros, o a cartografías militares. Fuentes todas ellas que, más directa o indirectamente, van a hablar de tierras que lindan con caminos concejiles, de normas y prácticas acerca del arreglo y composición de los caminos, de puentes y vados, del tráfico mulatero y carreteril, de las características y el estado de los viales, y, en general, de la estructura y las ramificaciones de una red viaria.

Precisamente, la abundancia de microtopónimos que suele aparecer en esa documentación, y el obvio interés por localizarlos espacialmente, conlleva la consideración de otro tipo de fuentes a menudo ausentes en los trabajos de caminería histórica: las fuentes orales. Cierto es que prácticamente todas las investigaciones con recurso al trabajo de campo suelen integrar, con cita o sin ella, informaciones orales espontáneas que resultan de gran ayuda a la hora de localizar restos camineros y viejos trazados. Pero esas mismas fuentes más trabajadas y seleccionadas, convertidas en entrevistas sistematizadas, pueden aportar además informaciones relevantes no sólo sobre la última fase funcional de viejos caminos, lo que incluye tráficos, vehículos o prácticas de composición, sino también, y especialmente, sobre la ubicación concreta de algunos de los microtopónimos aportados por la documentación escrita. Esa indagación microtoponímica, aparte de proporcionar una interpretación más espacial de los documentos de archivo, puede desembocar en una detallada cartografía toponímica de indudable interés para la reconstrucción de redes viarias.

Asimismo, a esa escala las fuentes arqueológicas también parecen pedir una reconsideración. A pesar de su probada validez, la asociación de restos camineros con cronotipologías está muy restringida, y no sin problemas como se ha visto, a ejes viarios principales y suprarregionales. Los caminos interregionales o locales, por el contrario, no es de esperar que reproduzcan las tipologías de los ejes principales, ni que necesiten la construcción de grandes puentes de piedra, ni tampoco que vayan jalonados con abundancia de hitos o edificaciones. En ese sentido, y de nuevo con la ayuda de la información oral, quizás sea más fructífero, si acaso posible, tratar de relacionar tipologías con usos más que con períodos históricos; es decir, tratar de identificar tipos de anchuras y afirmados con funciones determinadas. Igualmente, por lo que respecta a los vestigios de elementos asociados, si se tiene la suerte de haberlos y localizarlos, parece oportuno agudizar la mirada para exprimir al máximo la información que puedan contener, incluido sondeo o excavación arqueológica, pues a esa escala cualquier mínimo detalle puede dar lugar a la revisión de otras fuentes y a la elaboración de nuevas hipótesis, lo cual ya es mucho.

Por supuesto, el estudio de los caminos en esa línea no sólo exige un gran esfuerzo tanto de archivo y gabinete como de campo, más factible para grupos que para investigadores 
individuales, sino una buena paciencia, pues presumiblemente los resultados sean de largo plazo y muy lentos, avanzando de pequeñas en pequeñas hipótesis. Una línea que viene trazando el Grupo de Geografía Histórica del Paisaje (Universidad de Cantabria) sobre el valle de Lamasón, un municipio de media montaña en el Occidente de la comunidad cántabra, y que ya ha dado algún tímido fruto (Ansola et.al., 2002). Así, y por lo que respecta a los caminos, José Sierra y el que esto escribe han conseguido identificar los trazados y algunos de los restos de los caminos supralocales que unían el valle de Lamasón con otros términos, especialmente del principal de ellos, el camino real de La Montaña; y en la actualidad, además de continuar con la búsqueda de vestigios e informaciones más antiguas de esa red supralocal y de tener planteado un sondeo arqueológico sobre las ruinas de una vieja venta de montaña, trabajan en la reconstrucción de los trazados más locales o vecinales, los de los caminos entre núcleos, agrícolas, ganaderos, forestales o (pre)industriales. Lo demás lo tendrán que decir los resultados que de ahí vayan surgiendo.

\section{Agradecimientos}

El autor quiere agradecer al resto de los miembros del Grupo de Geografía Histórica del Paisaje de la Universidad de Cantabria (Manuel Corbera, Manuel Frochoso, Raquel González y José Sierra) el aprendizaje compartido dentro del curso de doctorado «Geografía histórica y arqueología del paisaje: un ensayo metodológico en la Cantabria rural», de donde sale el presente trabajo, así como sus fructíferos comentarios al primer borrador del mismo.

\section{Referencias bibliográficas}

ABÁSOLO, J.A. (1975): Comunicaciones de la época romana en la provincia de Burgos. Diputación Provincial de Burgos. Burgos, 253 pp.

AGACHE, R. (1971): Détection aérienne de vestiges protohistoriques gallo-romains et médiévaux dans le bassin de la Somme et ses abords. Numéro spécial du Bulletin de la Société de Préhistoire du Nord. Amiens, $230 \mathrm{pp}$.

ÁLVAREZ, E. y BLANCO, E. (1999): «Las vías de comunicación en Cantabria en la Edad Media», en I Encuentro de Historia de Cantabria. Universidad de Cantabria-Gobierno de Cantabria. Santander, I, pp. 491-521.

ALZOLA Y MINONDO, P. (1899): Historia de las obras públicas en España: estudio histórico. Colegio de Ingenieros de Caminos, Canales y Puertos-Turner. Madrid, 1979, $501 \mathrm{pp}$.

ANCHÓN, J.A. (1998): Historia de las vías de comunicación en Guipúzcoa, 2: Edad Moderna (1500-1833). Diputación Foral de Guipúzkoa. San Sebastián, 315 pp.

ANSOLA, A. et.al. (2002): «Contributi per la storia del paesaggio della montagna cantabrica: la valle del Lamasón», Archeologia postmedievale, $\mathrm{n}^{\circ}$ 6, pp. 89-102.

ARENAS, J.J. (2002): Caminos en el aire: los puentes. Colegio de Ingenieros de Caminos, Canales y Puertos. Madrid, 2 vols.

ARIÑO, E. et.al. (2004): El pasado presente: arqueología de los paisajes en la Hispania romana. Universidad de Salamanca-Universitat de Barcelona. Salamanca, $234 \mathrm{pp}$.

ARROYO ILERA, F. (1998): Agua, paisaje y sociedad en el siglo XVI según las Relaciones Topográficas de Felipe II. Ediciones del Umbral. Madrid, 246 pp.

BAHAMONDE, A. et.al. (1998): Atlas histórico de las comunicaciones en España, 1700-1998. Correos y Telégrafos. Barcelona, 304 pp.

BARRENA, E. (1991): Historia de las comunicaciones en Guipúzcoa, 1: Antigüedad y Medievo. Diputación Foral de Guipúzkoa. San Sebastián, 258 pp.

BELIL, M. y CLOS, I. (1983): «Notes a l'entorn del pensament de Carl O. Sauer (1889-1975)», Documents d'anàlisi geogràfica, $\mathrm{n}^{\mathrm{o}} 2$, pp. 177-188. 
BELLO, J.M. et.al. (1987): La cultura megalítica de la provincia de La Coruña y sus relaciones con el marco natural: implicaciones socioeconómicas. Diputación Provincial de La Coruña. La Coruña, $163 \mathrm{pp}$.

BLOCH, M. (1931): La historia rural francesa: caracteres originales. Crítica. Barcelona, 1978, $551 \mathrm{pp}$.

BROEK, J.O.M. (1943): «The Relations between History and Geography», Pacific Historical Review, $n^{\circ} 10$, pp. 321-325.

CABO, A. (2002): «Los caminos históricos y sus obstáculos fluviales», Estudios geográficos, $\mathrm{n}^{\circ}$ 248-249, pp. 471-492.

CARRERAS, C. y VILAGRASA, J. (1986): «La geografía histórica», en GARCÍA BALLESTEROS, A. (coord.): Teoría y práctica de la geografía. Alambra. Madrid, pp. 361-372.

CASADO SOTO, J.L. (1980): Cantabria vista por viajeros de los siglos XVI y XVII. Institución Cultural de Cantabria. Santander, 200 pp.

CASADO SOTO, J.L. (1986): Cantabria en los siglos XVI y XVII. Tantín. Santander, 315 pp.

CLARK, A.H. (1954): «Historical Geography», in JAMES, P.E. and JONES, C.F. (eds.): American Geography: inventory and prospects. Syracuse University Press. Syracuse, pp. 71-105.

CRESPO, M. et.al. (1999): «El camino real de Turujal (Hualle, Valdáliga)», Trabajos sobre el patrimonio histórico-artístico-comarcal, pp. 5-26.

CHEVALLIER, R. (1976): «Le paysage palimpseste de l'histoire: pour une archeologie du paysage», Mélanges de la Casa Velázquez, XII, pp. 503-510.

DURÁN, M. (2001): «La identificación de los puentes romanos en Hispania: una cuestión a desarrollar», OP Ingeniería y territorio, $\mathrm{n}^{\circ} 57$, pp. 4-13.

DURÁN, M. (2004): La construcción de puentes romanos en Hispania. Xunta de Galicia. Santiago de Compostela, $261 \mathrm{pp}$.

DURÁN, M. et.al. (1999): La vía Nova en la serra do Xurés: la rehabilitación de la vía Nova entre Portela do Home y Baños de Riocaldo (Ourense). Xunta de Galicia. Santiago de Compostela, $165 \mathrm{pp}$.

FEBVRE, L. (1953): Combates por la historia. Ariel. Barcelona, 1982, 246 pp.

FERNÁNDEZ TROYANO, L. (1994): Los pasos históricos de la sierra de Guadarrama. Colegio de Ingenieros de Caminos, Canales y Puertos. Madrid, $280 \mathrm{pp}$.

FERREIRA, E. (1988): Los caminos medievales de Galicia. Museo Arqueolóxico Provincial. Orense, $260 \mathrm{pp}$.

FONSECA, J.M. (1985): «Las calzadas romanas de acceso a Cantabria», Revista de arqueología, $\mathrm{n}^{\circ} 49$, pp. 23-35.

GARCÍA ALONSO, M. (1994): «Caminos y despoblados en el Alto Besaya», Trabajos de arqueología en Cantabria II, V, pp. 141-150.

GARCÍA ALONSO, M. (1999): «Los carboneros de los bosques de Cantabria», Litoral atlántico, $\mathrm{n}^{\circ} 2$, pp. 96-105.

GARCÍA ALONSO, M. (2002a): «El puerto de Los Tornos (Cantabria-Vizcaya-Burgos): nuevas y viejas evidencias arqueológicas en un espacio liminal y de tránsito», Trabajos de arqueología en Cantabria, V, pp. 195-207.

GARCÍA ALONSO, M. (2002b): «Hacia la arqueología del paisaje: dominio y uso del espacio rural en las Asturias de Santillana en la Edad Media», Edades, nº 10, pp. 45-74.

GARCÍA RAMÓN, M.D. (1985): «Sobre el legado tradicional de la geografía británica y norteamericana y su vigencia», en GARCÍA RAMÓN, M.D. (ed.): Teoría y método en la geografía humana anglosajona. Ariel. Barcelona, pp. 13-21.

GÓMEZ BÁRCENA, J. (2002): «La presura de Toporias (Udías, Cantabria)», Trabajos de arqueología en Cantabria, V, pp. 115-126.

GONZÁLEZ DE RIANCHO, J. (1988): La vía romana de El Escudo. Colegio Oficial de Arquitectos de Cantabria. Santander, $117 \mathrm{pp}$.

GUERÍN, P. (1971): «La venta de la Vega», Publicaciones del Instituto de Etnografía y Folklore «Hoyos Sainz», III, pp. 272-282.

IGLESIAS, J.M. y MUNIZ, J.A. (1992): Las comunicaciones en la Cantabria romana. Universidad de Cantabria-Librería Estvdio. Santander, 257 pp. 
IZQUIERDO, R. (1986): «El Real Consulado del Mar de Santander y las comunicaciones terrestres en Cantabria», en MARTÍNEZ VARA, T. (ed.): Mercado y desarrollo económico en al España contemporánea. Siglo XXI-Junta del Puerto de Santander. Madrid, pp. 159-176.

IZQUIERDO, R. (1996): El Real Consulado de Santander y el impulso de las obras públicas (una referencia al camino de La Rioja), 1785-1829. Autoridad Portuaria de Santander. Santander, $223 \mathrm{pp}$.

La imagen (1997) de Cantabria en el Archivo de la Real Chancillería de Valladolid. Fundación Santillana. Madrid, $94 \mathrm{pp}$.

MADRAZO, S. (1984): El sistema de transportes en España, 1750-1850. Colegio de Ingenieros de Caminos, Canales y Puertos-Turner. Madrid, 2 vols.

MAGALLÓN, M.A. (1999): «Las vías romanas en Aragón», en MAGALLÓN, M.A. (Coord.): Caminos y comunicaciones en Aragón. Institución «Fernando El Católico». Zaragoza, pp. 43-57.

MAISO, J. (1990): La difícil modernización de Cantabria en el siglo XVIII: D. Juan F. de Isla y Alvear. Ayuntamiento de Santander. Santander, 439 pp.

MENÉNDEZ, J.M. (1987): «El camino de Reinosa, 1750-1800», TTC, nº 26, pp. 23-31.

MENÉNDEZ PIDAL, G. (1951): Los caminos en la historia de España. Ediciones Cultura Hispánica. Madrid, $144 \mathrm{pp}$.

MENÉNDEZ, J. y SORIA, A. (1994): «El territorio como artificio cultural: corografía histórica del Norte de la Península Ibérica», Ciudad y territorio-Estudios territoriales, nº 99, pp. 63-94.

MINGOTE, J.L. (1996): «Áreas de uso y cambios técnicos: el caso del carro chillón en España», en FRAGUAS, A. y FIDALGO, X.A. (coords.): Tecnoloxía tradicional: dimensión patrimonial e valoración antropolóxica: Actas do Simposio Internacional In Memoriam Xaquín Lorenzo. Consello da Cultura Galega. Santiago de Compostela, pp. 67-104.

MOLÉNAT, J.P. (1971): «Chemins et ponts du Nord de la Castille au temps des Rois Catholiques», Mélanges de la Casa Velázquez, VII, pp. 115-162.

MORENO, I. (2004): Vías romanas: ingeniería y técnica constructiva. Ministerio de Fomento. Madrid, $241 \mathrm{pp}$.

MUÑIZ, J.A. (1999): «Articulación del espacio en la Cantabria prerromana y romana: red viaria y territorio», en I Encuentro de Historia de Cantabria. Universidad de Cantabria-Gobierno de Cantabria. Santander, I, pp. 291-306.

NÁRDIZ, C. (1992): El territorio y los caminos en Galicia: planos históricos de la red viaria. Colegio de Ingenieros de Caminos, Canales y Puertos de Galicia-Xunta de Galicia. La Coruña, 477 pp.

OREJAS, A. (1995): Del «marco geográfico» a la arqueología del paisaje: la aportación de la fotografía aérea. Consejo Superior de Investigaciones Científicas. Madrid, 152 pp.

PALACIO ATARD, V. (1960): El comercio de Castilla y el puerto de Santander en el siglo XVIII (notas para su estudio). Consejo Superior de Investigaciones Científicas. Madrid, 206 pp.

PALET, J.M. (1996): «Análisis arqueomorfológico de la red viaria en el Llano de Barcelona: secuencias relativas, estructuración y evolución del territorio», en CRIADO DEL VAL, M. (dir.): Caminería Hispánica: Actas del II Congreso Intenacional de Caminería Hispánica, tomo I, Caminería física. Patronato Arcipreste de Hita-Asociación Técnica de Carreteros. Madrid, pp. 27-36.

PALET, J.M. (1998): «Les empremtes del paisatge», L'avenç, nº 231, pp. 73-77.

PRATS, A. y SÁNCHEZ, M. (1985): «El camino de Bárcena Mayor a Campoo», en Obras públicas de Cantabria. Escuela Técnica Superior de Ingenieros de Caminos, Canales y Puertos-Fundación Leonardo Torres Quevedo. Santander, pp. 29-38.

QUIRÓS, F. (1971): «Fuentes para la geografía de la circulación en España: algunos libros sobre los caminos españoles de los siglos XVIII y XIX», Estudios geográficos, nº 123, pp. 353-373.

ROLDÁN, J.M. (1975): Itineraria Hispana: fuentes antiguas para el estudio de las vías romanas en la Península Ibérica. Universidad de Valladolid-Universidad de Granada. Madrid, 279 pp.

RUIZ, M.L. y DEL JESÚS, M. (2001): Puente Agüero: crónica de una rehabilitación. Siec. Torrelavega, $67 \mathrm{pp}$.

RUIZ, A. y FERNÁNDEZ, F. (2002): «Viejos caminos del valle de Villaverde en su relación con algunos aspectos históricos», Trabajos de arqueología en Cantabria, V, pp. 149-161.

SÁNCHEZ TRUJILLANO, M.T. (1976): «Humilladeros de La Montaña: los «Santucos de las Ánimas»», Publicaciones del Instituto de Etnografía y Folklore «Hoyos Sainz», VIII, pp. 259-276. 
SÁNCHEZ TRUJILLANO, M.T. (1977-1978): «Los humilladeros de La Montaña: los «Santucos de la Pasión»», Publicaciones del Instituto de Etnografía y Folklore «Hoyos Sainz», IX, pp. 71-88.

SÁNCHEZ TRUJILLANO, M.T. (1979-1981): «Los humilladeros de La Montaña: «las Cruces»», Publicaciones del Instituto de Etnografía y Folklore «Hoyos Sainz», X, pp. 115-153.

SÁNCHEZ, J.I. y GONZÁLEZ, E. (2003): Humilladeros de la provincia de Valladolid. Diputación de Valladolid. Valladolid, $497 \mathrm{pp}$.

SAUER, C. (1925): «The Morphology of Landscape», in LEIGHLY, J. (ed.): Land and Life: a Selection from the Writings of Carl Ortwin Sauer. University of California Press. Berkeley, 1965, pp. 315-350.

SAUER, C. (1931): «La geografía cultural», en GÓMEZ MENDOZA, J. et.al.: El pensamiento geográfico: estudio interpretativo y antología de textos (de Humboldt a las tendencias radicales). Alianza. Madrid, 1988, pp. 349-354.

SAUER, C. (1941): «Foreword Historical Geography», in LEIGHLY, J. (ed.): Land and Life: a Selection from the Writings of Carl Ortwin Sauer. University of California Press. Berkeley, 1965, pp. 351-379.

SERENO, P. (1981): «L'archeologia del paesaggio agrario: una nuova frontiera di recerca», en Campagna e industria: $i$ segni del lavoro. Touring Club Italiano, Milano, pp. 24-47.

SILLIERES, P. (1976): «La via Augusta de Cordue à Cadix: documents du XVIII ${ }^{\mathrm{e}}$ S. et photographies aeriennes pour une etude de topographie historique», Mélanges de la Casa Velásquez, XII, pp. 27-67.

SILLIÈRES, P. Les voies de communication de l'Hispanie meridionale. Publications du Centre Pierre Paris. Paris, 904 pp.

SOJO Y LOMBA, F. (1947): «De Re Toponimia: comunicaciones en Cantabria», Boletín de la Real Sociedad Geográfica, LXXXIII, pp. 7-71.

TRUEBA, A. (1993): Las comunicaciones terrestres en la Cantabria de la segunda mitad del siglo XVIII (algunos proyectos de articulación interna del espacio regional). Universidad de Cantabria. Tesis doctoral inédita, $416 \mathrm{pp}$.

URIOL, J.I. (1992): Historia de los caminos de España. Colegio de Ingenieros de Caminos, Canales y Puertos. Madrid, 2 vols.

VAQUERIZO, M. (1988): «Ruina y reconstrucción del puente de Santa María de Cayón en la Edad Moderna», Altamira, XLVII, pp. 309-353.

VIDAL DE LA BLACHE, P. (1902): Discours prononcé à la séance générale du Congrés des Sociétés Savantes. Imprinerie Nacional. Paris, 18 pp.

WHITTLESEY, D. (1929): «Sequent Occupance», Annals of the Association of American Geographers, vol. 19, pp. 162-165. 